\title{
РАННЯЯ ДИАГНОСТИКА НАРУШЕНИЙ УГЛЕВОДНОГО ОБМЕНА У РЕБЕНКА С МУТАЦИЕЙ В ГЕНЕ НNF1A (MODY3)
}

\author{
Бричева Э.Б., Зильберман Л.И.
}

ФГБУ «Национальный медицинский исследовательский центр эндокринологии» Минздрава России

Сахарный диабет тип MODY3- это моногенная форма СД с аутосомно-доминантным типом наследования, обусловлен мутациями в гене $H N F 1 A$ и является одним из наиболее частых вариантов MODY. Ген HNF1A кодирует ядерный фактор гепатоцитов 1 альфа (HNF1A), который в свою очередь регулирует в b-клетках экспрессию множества генов, участвующих в метаболизме и транспорте глюкозы (GLUT2, INS и дp). Для MODY3 характерна не только генетическая, но и фенотипическая гетерогенность.

Клинический случай: У девочки 3 лет при обследовании после перенесенной кишечной инфекции обнаружено повышение гликемии натощак до 7 ммоль/л, после приема пищи 9,2 ммоль/л, максимально 23,4 ммоль/л в течение дня. В связи с отягощенной наследственностью мама регулярно самостоятельно измеряла гликемию. При госпитализации гликемия 8,0 ммоль/л, гликированный гемоглобин - 5,0\%. Проведен пероральный глюкозотолерантный тест (ПГТТ): гликемия натощак 5,8 ммоль/л, через 120 мин - 5,3 ммоль/л, инсулин натощак 14,2 мкМЕ/мл, через 180 мин - 8,14 мкME/мл, С-пептид натощак 0,47 нмоль/л, через 120 мин - 0,75 нмоль/л. Через 10 месяцев НbА1C 5,6\%, ПГТТ: гликемия натощак 5,3 ммоль/л, через 120 мин - 4,3 ммоль/л, инсулин натощак 13,09 меМЕ/мл, через 180 мин - 5,16 мкМЕ/мл, С-пептид натощак 1,08 нмоль/л, через 120 мин - 1,03 нмоль/л.

Рекомендована диета с ограничением легкоусвояемых углеводов, через год $\mathrm{HbA1C}$ - 5,9\%, специфические панкреатические аутоантитела (ICA, GAD, IAA) - отрицательные.

Через 15 месяцев госпитализирована в ФГБУ "НМИЦ эндокринологии" Минздрава России. При обследовании рост: 118.3 см (SDS 2.061,); вес: 21.0 кг; ИМТ: 15.0 кг/м2; (SDS -0.122); HbA1C- 5,3\%.

Из анамнеза жизни известно, что при рождении вес 3780г, рост -53 см. Отягощен семейный анамнез по аутосомно-доминантному типу по линии отца: сахарный диабет в трех поколениях, у отца диагностирован в 29 лет, у других родственников с 34 до 40 лет, получают терапию инсулином и/или препаратами сульфонилмочевины.

Мама отмечает, что за весь период наблюдения (с января 2020г) было 3-4 эпизода гипогликемий (до 2,2-2,9 ммольاл), обусловленных длительным голодным промежутком, судороги и/или потери сознания отрицают.

Проведен ПГТТ: гликемия натощак 2,94 ммоль/л, через 30 мин - 10,35 ммоль/л, через 60 мин - 13,12 ммоль/л, через 90 мин - 10,52 ммоль/л, через 120 мин - 9,3 ммоль/л, инсулин натощак 3,84 мкМЕ/мл, через 30 мин - 77,55, через 60 мин - 140,1 мкМЕ/мл, через 90 мин - 102 мкМЕ/мл, через 120 мин - 74,9 мкМЕ/мл, С-пептид натощак - 0,809 нмоль/л, через 30 мин - 5,78 нмоль/л,

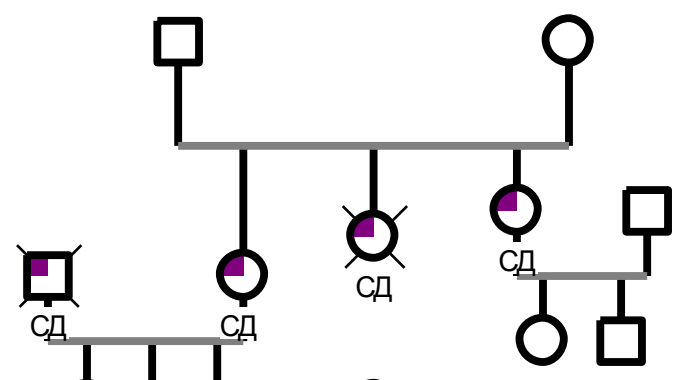
через 60 мин - 10,34 нмоль/л, через 90 мин - 9,43 нмоль/л, через 120 мин - 7,55 нмоль/л. У пациентки выявлено нарушение толерантности к углеводам, секреция инсулина и C-пептида сохранная, высокая. 
В связи с гипогликемиями в анамнезе проведена проба с голоданием. Голодный промежуток составил 20 часов, гликемия 3,5 ммольЛ, с-пептид 0,33 нг\мл, инсулин 0,83 мкЕд\мл, кетоны 2,6 ммольҢ. Гиперинсулинизм исключен, отмечался кетоз.

Специфические аутоантитела (ICA, GAD, IA2, IAA, ZnT8) - отрицательные.

Произведено типирование генов DRB1, DQA1, DQB1, HLA класса II: DRB1*04, DQA1*0301, DQB1*0302; DRB1*07, DQA1*0201, DQB1*02, выявлен предрасполагающий гаплотип к СД 1 типа. Учитывая нетипичное течение заболевания, отсутствие повышения титра специфических аутоантител и отягощенный семейный анамнез проведено секвенирование панели «Сахарный диабет» (27 генов) и в гене HNF1A (NM 000545.8) в 8 интроне обнаружена миссенс-мутация в гетерозиготном состоянии с.1624-14C>T .

Через 2 года с момента диагностики нарушений углеводного обмена у пациентки на фоне соблюдения ограничения легкоусвояемых углеводов, но с исключением длительных перерывов в приеме углеводов гликемия натощак 4,9-5,5 ммоль/л, после еды от 6,4 до 10,3 ммоль/л, НbА1С$5,6 \%$.

\section{Заключение:}

Для данного типа MODY характерно постепенное снижение функции b-клеток и b-клеточной пролиферации, клинически проявляющейся в прогрессирующем нарушении углеводного обмена с относительно поздней манифестацией, как правило, после 25 лет. У пациентов с MODY3 степень секреции инсулина и течение заболевания может сильно варьировать даже у представителей одной семьи. Такая гетерогенность обусловлена большим количеством генов, экспрессию которых регулирует $H N F 1 A$, и возможными модификациями в структуре этих генов. В семье пациентки также присутствует вариабельность фенотипической картины заболевания - возраст дебюта от 29 до 41 года, компенсация У $\backslash \mathrm{B}$ обмена на ПССП и необходимость инсулинотерапии. В клинической картине заболевания у пациентки, наряду с постпрандиальными гипергликемиями с повышенной секрецией инсулина, присутствуют гипогликемии, обусловленные длительными перерывами в приеме пищи. У пациентов с мутациями в гене HNFIA описываются гиперинсулинемические гипогликемии (Kapoor и соавт, 2008), в описываемом случае гипогликемии носили кетотический нормоинсулинемический характер.

В мировой литературе самый ранний случай манифестации MODY3 описан у пациента в возрасте 7 лет (Pearson и соавт, 2012). В данном клиническом случае перенесенная инфекция, а также настороженность мамы в отношении сахарного диабета, привели к очень раннему выявлению нарушений углеводного обмена до появления классических симптомов СД. 